\title{
Influence of the physical state of a polymer blend on thermal ageing
}

Geraldine Rapp ${ }^{1}$, Jonathan Tireau ${ }^{3}$, Pierre-Olivier Bussiere ${ }^{1}$, Jean-Marc Chenal ${ }^{2}$, François

Rousset $^{4}$, Laurent Chazeau ${ }^{2}$, Jean-Luc Gardette ${ }^{1}$, Sandrine Therias* ${ }^{1}$

1 Université Clermont Auvergne, CNRS, SIGMA Clermont, ICCF, F-63000 ClermontFerrand, France

2 Université de Lyon, INSA Lyon, MATEIS, UMR CNRS 5510, 7 avenue Jean Capelle, F69621 Villeurbanne, France

3 EDF R\&D, Materials and Mechanics of Components Department, Chemistry and Materials for energy efficiency Group, Avenue des Renardières, F-77818 Moret-sur-Loing, France

4 Université de Lyon, INSA Lyon, CETHIL, UMR CNRS 5008, 9 rue de la Physique, F69621 Villeurbanne, France

\begin{abstract}
Crosslinked linear polyethylene/branched polyethylene blends have been studied by thermooxidation at different temperatures (between $60^{\circ} \mathrm{C}$ and $110^{\circ} \mathrm{C}$ ), which are either below or above the melting temperature of each polyethylene in the blend.

The modifications of the chemical structure of both polyethylenes and the blends were monitored by infrared spectroscopy during thermo-oxidation. The same oxidation products could be identified between the linear polyethylene and the branched polyethylene. Chemical derivatization treatments allowed confirming the thermo-oxidation mechanism of polyethylene and the same oxidation products for both polyethylenes. By using an Arrhenius approach, it has been shown that accelerated ageing above $80^{\circ} \mathrm{C}$ is not representative of thermal ageing below this temperature. Moreover, it was shown that there was no influence of the physical state of the polymer during thermal ageing on the observed non-Arrhenius behavior. Thus, extrapolating accelerated ageing tests to lower temperatures by an Arrhenius approach in order to predict the lifetime of the polymer leads to critical errors.
\end{abstract}

Keywords polyethylene ; crosslinked; thermo-oxidation; Arrhenius; physical state

* Corresponding Author: Sandrine Therias

I.C.C.F. UMR 6296 - Institut de Chimie de Clermont-Ferrand

Université Clermont Auvergne - CNRS - SIGMA Clermont

Campus des Cézeaux - 24, avenue Blaise Pascal - TSA 60026 - CS 60026

63178 Aubière Cedex

E-mail: $\underline{\text { sandrine.therias@uca.fr }}$ 


\section{Introduction}

Polymer materials are used in many different fields due to their excellent performances, such as low weight and easy processing, associated to low cost and inertness. Polyethylene (PE) is one of the most common, widespread and most inexpensive thermoplastic polymers used for industrial applications. Specifically, crosslinked polyethylene is the base compound for cable insulation manufacturing since it maintains the good dielectric property of the original polymer, and has good mechanical properties and thermal stability. During last years, new regulatory requirements and cost considerations led to the development of new polymeric materials by the cable industry. Among them, blends of crosslinked linear polyethylene with branched polyethylene are intended for replacing part of the currently used EPDM insulating part of the K1 qualified electric cables in nuclear power plants. Indeed, due to the large variety of available molecular architectures of polyethylenes (depending on various types of polymerization methods), a very large panel of mechanical and thermal properties is available through their blending [1-3].

Thermal oxidation is one of the most frequent and important stresses that affect polymer properties, particularly when they are used as electrical insulating materials. Under its working conditions, the cable is permanently subjected to thermal ageing (between 50 and $70^{\circ} \mathrm{C}$ inside the reactor building), which can cause irreversible damages to the polyethylene insulant of the cable.

Much work has been carried out on the analysis of thermally induced oxidation of polyethylene [4-8]. It is generally admitted that chemical degradation has consequences at upper scales and affects both macromolecular architecture $[9,10]$ and crystalline morphology and microstructure [11-15], with subsequent effects on the mechanical behavior such as, for instance, embrittlement [16]. Thermal ageing of crosslinked polyethylene has also been studied, to a lesser extent [17-19]. Thermal oxidation leads to a decrease of the gel fraction resulting from a chain scission process $[17,19]$ and an increase of the overall crystallinity ratio $[19,20]$ which is usually ascribed to chemi-crystallization and/or annealing phenomena. Some changes in the physical properties such as discolouration, volume shrinkage and brittleness have also been observed [21]. Thermal ageing also leads to the deterioration of electrical and mechanical properties [22,23].

All these previous works were performed at elevated temperatures in order to increase the oxidation rate of the polymers. Sometimes, these data are used to extrapolate material performance to use conditions of the polymer and predict its lifetime. This method requires 
that the mechanisms occuring during accelerated ageing are the same as those during ageing in service conditions. However, polymer oxidation depends on simultaneous chemical and physical reactions and accelerative conditions add complexity to this phenomenon. There have been numerous studies over the past 20 years that mention non-Arrhenius behaviors for non-crystalline and crystalline polymers, where a linear relationship is insufficient to match the observed aging data [24-30].

In the case of semi-crystalline materials such as polyethylene, increasing the temperature may also change the physical state of the polymer, i.e. the crystalline microstructure and ratio. In the case of polyethylenes blends having several melting temperatures, increasing the temperature during accelerated ageing tests may lead to a partial or complete melting of the crystallites. Therefore, this also questions the representativeness of accelerated ageing tests with respect to natural ageing in use conditions.

Thus, the aim of this work is to study the degradation in thermooxidative conditions of a crosslinked linear polyethylene/branched polyethylene blend. The validity of accelerated ageing in comparison with natural ageing will be investigated using an Arrhenius approach. This question is addressed here by using different ageing temperatures, which are either below or above the melting temperature of each polyethylene in the blend. Therefore, the influence of the physical state of the polymer on the ageing mechanism and kinetics will be addressed as well as the following questions : under which conditions accelerated ageing experiments still have their predictive value ? Does the physical state of the polymer have an influence on the ageing mechanism and the kinetics ? Is accelerated ageing representative of natural ageing in service conditions?

\section{Experimental section}

\subsection{Materials}

The linear polyethylene, hereafter called PE (LLDPE 324CE), was supplied by SABIC ${ }^{\circledR}$ and the branched polyethylene, hereafter called PEcB (DM940), was supplied by TAFMER ${ }^{\mathrm{TM}}$. Both polyethylenes are copolymers of ethylene and butene, respectively $3.4 \%$ and $9.4 \%$ of butene for PE and PEcB, determined by ${ }^{1} \mathrm{H}$ and ${ }^{13} \mathrm{C}$ NMR spectroscopy [31] according to Nuanthanom's method [32].

The molar masses of both polyethylenes were estimated by SEC using 1,2,4 trichlorobenzene as an eluent in a column at $150^{\circ} \mathrm{C}$ at a flow rate of $0.6 \mathrm{~mL} / \mathrm{min}$ and the calculated masses were 
$M_{n}=20000$ g.mol ${ }^{-1}, M_{w}=73000$ g.mol ${ }^{-1}$ for PE and $M_{n}=22000$ g.mol ${ }^{-1}, M_{w}=62000$ g. $\mathrm{mol}^{-1}$ for PEcB.

Dicumyl peroxide (DCP, Arkema Luperox $®)$ was used as crosslinking agent.

\subsection{Processing}

PE/PEcB blends of 100/0, 70/30, 50/50, 30/70, 0/100 wt \% were prepared at the Nexans Research Center (Lyon). Pellets were processed in an external mixer at a temperature of $120^{\circ} \mathrm{C}$ and were mixed with $2 \mathrm{wt} . \%$ DCP for 8 to $10 \mathrm{~min}$.

Afterwards, the samples were calendered and then compression-molded at $180^{\circ} \mathrm{C}$ under 200 bars for $6.5 \mathrm{~min}$, according to moving die rheometry results $(6.5 \mathrm{~min}$ is the time needed to obtain $98 \%$ of the maximum torque). $80 \mu \mathrm{m}$ thick films were obtained using moulds for spectroscopy analysis. Thick sheets of 400-500 $\mu \mathrm{m}$ were used for other experiments (DSC, gel fraction, rheology...).

The same process was carried out without DCP in order to obtain sheets of non-crosslinked blends.

The composition of the blends is listed in Table 1.

Table 1 - Composition of the blends.

\begin{tabular}{|c|c|c|}
\hline Blend composition (wt. \%) & Non-crosslinked samples & Crosslinked samples* \\
\hline $100 \%$ PE & PE & PEr \\
\hline $70 \%$ PE - 30\% PEcB & 7030 & $7030 \mathrm{r}$ \\
\hline $50 \%$ PE - 50\% PEcB & 5050 & $5050 \mathrm{r}$ \\
\hline $30 \% \mathrm{PE}-70 \% \mathrm{PEcB}$ & 3070 & $3070 \mathrm{r}$ \\
\hline $100 \% \mathrm{PEcB}$ & $\mathrm{PEcB}$ & $\mathrm{PEcBr}$ \\
\hline
\end{tabular}

*including 2 wt. \% DCP

\subsection{Thermal ageing}

Thermal oxidation of the samples was carried out in air-circulation ovens at five different temperatures: $60^{\circ} \mathrm{C}, 80^{\circ} \mathrm{C}, 90^{\circ} \mathrm{C}, 100^{\circ} \mathrm{C}$ and $110^{\circ} \mathrm{C}$.

These temperatures have been chosen in order to vary the physical state of each polymer in the blend during thermal ageing and to operate below and above the melting points of the polyethylenes. 


\subsection{Characterization techniques}

\section{$\underline{I R \text { spectroscopy }}$}

Infrared spectra were recorded in transmission mode with a Nicolet 6700 FTIR spectrometer, working with OMNIC software, on $80 \mu \mathrm{m}$ thick films. Spectra were obtained using 32 scans and a $2 \mathrm{~cm}^{-1}$ resolution.

\section{Chemical derivatization treatments}

The thermo-oxidized samples were submitted to various chemical treatments in order to identify the degradation products. The aged $\mathrm{PEr}$ and $\mathrm{PEcBr}$ films were exposed to reactive gases such as ammonia $\left(\mathrm{NH}_{3}\right)$ and sulfur tetrafluoride $\left(\mathrm{SF}_{4}\right)$ at room temperature in a simple flow system that could be sealed off to permit the reaction to proceed. $\mathrm{SF}_{4}$ and $\mathrm{NH}_{3}$ treatments were carried out in an all-Teflon system. As a reference, unaged PEr and PEcBr films were submitted to the same treatment to check that no reaction occurred with the reactive gases. As illustrated hereafter, the reaction of $\mathrm{NH}_{3}$ with any carboxylic acid, ester or anhydride endgroups leads to the formation of ammonium carboxylates and/or amide groups, respectively $[33,34]$.

$$
\begin{aligned}
& \mathrm{R}-\mathrm{COO}-\mathrm{H}+\mathrm{NH}_{3} \quad \rightarrow \quad \mathrm{R}-\mathrm{COO}^{-}, \mathrm{NH}_{4}{ }^{+} \\
& \mathrm{R}-\mathrm{COO}-\mathrm{R}^{\prime}+\mathrm{NH}_{3} \quad \rightarrow \quad \text { R-CO-NH} \mathrm{N}_{2}+\mathrm{R}^{\prime}-\mathrm{OH} \\
& \mathrm{R}-\mathrm{CO}-\mathrm{O}-\mathrm{CO}-\mathrm{R}^{\prime}+2 \mathrm{NH}_{3} \rightarrow \quad \rightarrow \quad \mathrm{R}-\mathrm{COO}^{-}, \mathrm{NH}_{4}{ }^{+}+\mathrm{R}^{\prime}-\mathrm{CO}-\mathrm{NH}_{2}
\end{aligned}
$$

The resulting ammonium carboxylates are then characterized by an infrared absorption band between 1545 and $1560 \mathrm{~cm}^{-1}$ while the amide groups present among others, two characteristic absorption bands at 1670 and $1630 \mathrm{~cm}^{-1}$.

Besides, the reaction of carboxylic acid with $\mathrm{SF}_{4}$ leads to the formation of acid fluorides $[33,34]$. This treatment allows differentiating aliphatic acids from unsaturated acids. Aliphatic acid fluorides are characterized by an infrared absorption band around $1845 \mathrm{~cm}^{-1}$, whereas unsaturated acid fluorides have an infrared absorption band around $1815 \mathrm{~cm}^{-1}$.

$$
\mathrm{R}-\mathrm{COO}-\mathrm{H}+\mathrm{SF}_{4} \quad \rightarrow \quad \mathrm{R}-\mathrm{CO}-\mathrm{F}+\mathrm{HF}+\mathrm{SOF}_{2}
$$

Thermo-oxidized films were also treated with a solution of 2,4-dinitrophenylhydrazine $(2,4-$ DNPH) in methanol for $2 \mathrm{~h}$. This chemical treatment allows to identify aldehydes and ketones as oxidation products. DNPH reacts with aldehyde and ketone groups to give dinitrophenylhydrazones. This product is characterized by infrared absorption bands at 1618 
$\mathrm{cm}^{-1}(v(\mathrm{C}=\mathrm{N}))$ and $1594 \mathrm{~cm}^{-1}(v(\mathrm{C}=\mathrm{C}))$ and a strong UV-visible absorption band at $365 \mathrm{~nm}$. Before DNPH treatment, the samples were first immersed in methanol solution.

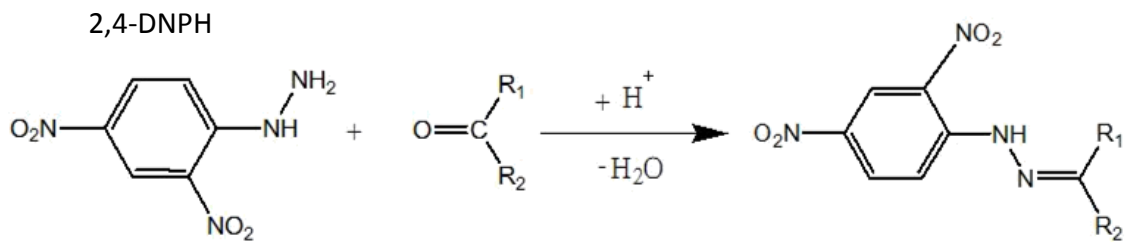

\section{$\underline{U V \text {-visible spectroscopy }}$}

UV-visible spectra were recorded on a Shimadzu UV-2600 scanning spectrophotometer equipped with an integrating sphere, working with UVProbe software. Spectra were recorded between 200 and $800 \mathrm{~nm}$ using a $0.5 \mathrm{~nm}$ resolution.

\section{Differential Scanning Calorimetry (DSC)}

Differential scanning calorimetry was performed using a Mettler Toledo DSC 822 device on the $500 \mu \mathrm{m}$ sheets, heated from $-20^{\circ} \mathrm{C}$ to $160^{\circ} \mathrm{C}$ at a heating rate of $10^{\circ} \mathrm{C} / \mathrm{min}$ under air flow. Samples crystallinity was calculated from the melting peak recorded during the DSC scan using the following equation (1):

$$
\chi(\%)=\frac{\Delta H m}{\Delta H m_{100 \%}} \times 100
$$

with $\chi$ is the weight fraction crystallinity, $\Delta \mathrm{H}_{\mathrm{m}}$ is sample melting enthalpy (deduced from the area of the melting peak) and $\Delta \mathrm{H}_{\mathrm{m} 100 \%}$ is the melting enthalpy for a $100 \%$ crystalline PE. A standard melting enthalpy of $290 \mathrm{~J} / \mathrm{g}$ has been used for $\Delta \mathrm{H}_{\mathrm{m} 100 \%}$ [35].

\section{Rheology in the melt state}

Rheology experiments in the melt state were performed at CETHIL (Centre d'Energétique et de Thermique de Lyon) using an Anton Paar MCR 702 TwinDrive in parallel plate geometry. The $25 \mathrm{~mm}$ diameter top plate and the $50 \mathrm{~mm}$ diameter bottom plate are at a distance of 0.5 $\mathrm{mm}$. Experiments were carried out between $300 \mathrm{rad} / \mathrm{s}$ and $0.1 \mathrm{rad} / \mathrm{s}$ at $140^{\circ} \mathrm{C}$ with a shear-rate of 5\% under nitrogen flow. The curves were computed according to standard methods. Zeroshear viscosity $\eta^{0}$ was computed from the complex viscosity curve $\eta^{*}=f(\omega)$ using the phenomenological Cross model [2] (equation 2):

$$
\eta^{*}=\eta^{0} /\left[1+(\lambda \omega)^{1-\mathrm{n}}\right]
$$

where $\eta^{0}$ is the zero-shear viscosity, $\lambda$ the relaxation time related to the longest relaxation time, $\omega$ is the frequency and $\mathrm{n}$ is an exponent $(\mathrm{n} \approx 0.5)$. 
Tests were run on non-crosslinked samples in order to characterize the miscibility of the two polyethylenes in the blends in the melt state. The G', G', and $\eta^{*}$ curves are displayed in Annex A.

\section{Results and discussion}

\subsection{Part 1: characterization of polymers and blends before ageing}

\subsubsection{Crystallinity}

\subsection{1.a Influence of comonomer content}

The thermal properties of PE, PEcB and the blends were investigated by DSC (Figure 1). PE and PEcB display different DSC thermograms, particularly in terms of shape of the melting peaks, melting temperatures and crystallinity degree [21].

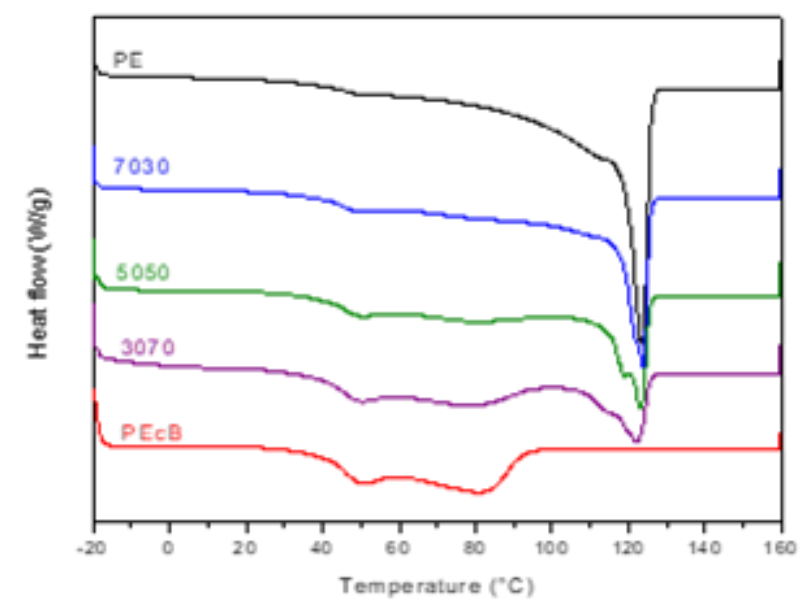

Fig. 1 - DSC thermograms of the two polymers and the three blends.

In the case of PE sample, the melting peak is quite asymmetric, with a large distribution towards the lower temperatures, which is attributed to a large distribution of crystallites thickness [21]. In the case of $\mathrm{PEcB}$ with higher comonomer contents, the melting endotherm is broad and shifted to lower temperatures ; the main melting peak temperature of $\mathrm{PE}$ is $124^{\circ} \mathrm{C}$ and the $\mathrm{PEcB}$ melting peaks are $42^{\circ} \mathrm{C}$ and $81^{\circ} \mathrm{C}$. Increasing the comonomer content also leads to a decrease of the melting temperatures and crystallinity degree of the material (51\% for PE and $27 \%$ for $\mathrm{PEcB}$ ) (Table 2). This is consistent with previous studies [37,38] and can be explained by the decrease of the average number of consecutive ethylene units when the comonomer content increases, which makes smaller the length of the crystallizable part of the copolymer chain. As a consequence, less perfect and smaller and less stable crystallites are formed during crystallization. The double melting peak of PEcB was also found for ethylene- 
octene copolymers [36-41] as well as for ethylene-butene copolymers [42,43]. The high temperature melting peak can be related to lamellar crystals made of the longest ethylene sequences while the low temperature peak can be attributed to fringed-micellar or «bundlelike $\gg$ crystals.

Table 2 - Melting temperatures and crystallinity of $500 \mu \mathrm{m}$-thick non-crosslinked polymers and blends.

\begin{tabular}{|c|c|c|c|}
\hline & $\mathbf{T}_{\mathbf{m} 1}\left({ }^{\circ} \mathbf{C}\right)$ & $\mathbf{T}_{\mathbf{m} 2}\left({ }^{\circ} \mathbf{C}\right)$ & Crystallinity (\%) \\
\hline $\mathbf{P E}$ & - & 124 & $51 \pm 1$ \\
\hline $\mathbf{7 0 3 0}$ & - & 124 & $42 \pm 2$ \\
\hline $\mathbf{5 0 5 0}$ & 80 & 123 & $41 \pm 2$ \\
\hline $\mathbf{3 0 7 0}$ & 80 & 122 & $37 \pm 2$ \\
\hline PEcB & 81 & - & $27 \pm 1$ \\
\hline
\end{tabular}

For the three blends, the heating curves display a high temperature and two low temperatures melting endotherms that roughly correspond to the two individual polymers. This suggests a phase separation in the blends, at least at the scale of the crystallites. Crystallinity degree and melting temperatures of the two polymers and the three blends are summarized in Table 2.

\subsection{1.b Influence of crosslinking}

DSC thermograms of $\mathrm{PE}$ and $\mathrm{PEcB}$ and of their crosslinked homologue are compared in Figure 2. For both polyethylenes, crystallinity degree decreases after crosslinking: from $51 \%$ to $40 \%$ for PE, and from $27 \%$ to $25 \%$ for $\mathrm{PEcB}$ (Table 3). Melting temperatures are also modified after the crosslinking process: from $124^{\circ} \mathrm{C}$ to $115^{\circ} \mathrm{C}$ for $\mathrm{PE}$, and from $81^{\circ} \mathrm{C}$ to $78^{\circ} \mathrm{C}$ for the high temperature peak of PEcB. In the blends, crosslinking also leads to a decrease of the melting temperature, i.e. of the crystal size, and of the crystallinity. 

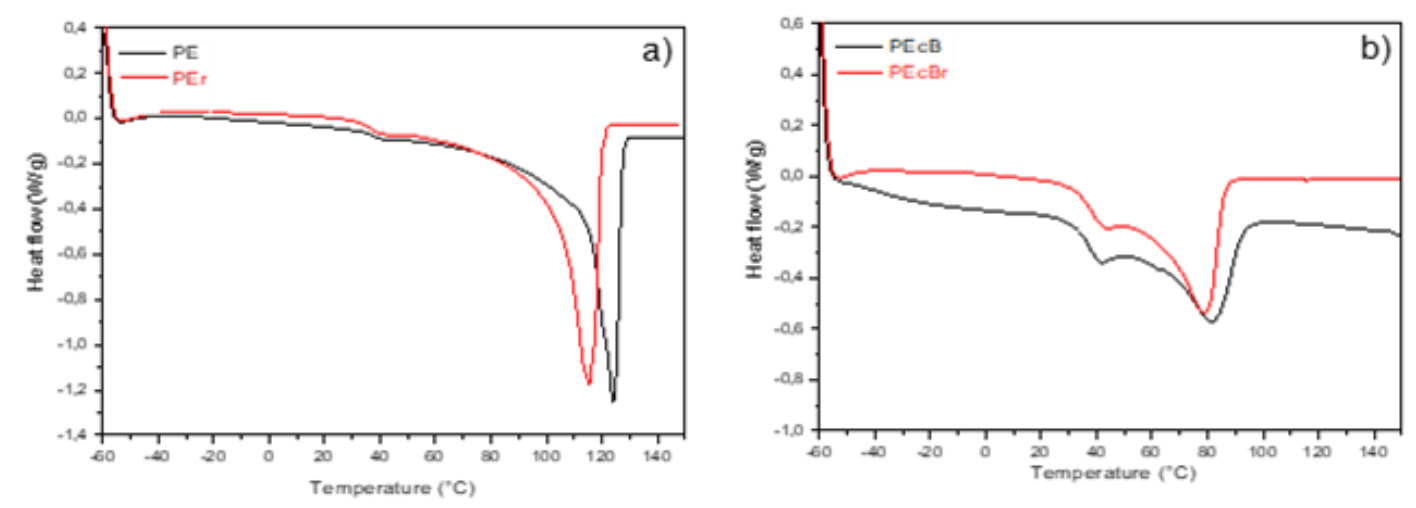

Fig. 2 - DSC thermograms of a) PE and crosslinked PEr b) PEcB and crosslinked PEcBr.

Table 3 - Melting temperatures and crystallinity of $500 \mu$ m-thick samples before and after crosslinking.

\begin{tabular}{|c|c|c|}
\hline & $\mathbf{T}_{\mathbf{m}}\left({ }^{\circ} \mathbf{C}\right)$ & Crystallinity (\%) \\
\hline $\mathbf{P E} / \mathbf{P E r}$ & $124 / 115$ & $51 \pm 1 / 40 \pm 1$ \\
\hline $\mathbf{7 0 3 0} / \mathbf{7 0 3 0 r}$ & $124 / 112$ & $42 \pm 2 / 35 \pm 2$ \\
\hline $\mathbf{5 0 5 0} / \mathbf{5 0 5 0 r}$ & $123 / 109$ & $41 \pm 2 / 32 \pm 1$ \\
\hline $\mathbf{3 0 7 0} / \mathbf{3 0 7 0 r}$ & $122 / 104$ & $37 \pm 2 / 30 \pm 2$ \\
\hline $\mathbf{P E c B} / \mathbf{P E c B r}$ & $81 / 78$ & $27 \pm 1 / 25 \pm 1$ \\
\hline
\end{tabular}

These results are also consistent with litterature [44-46] : crosslinking hinders the crystal growth as they create supplementary defects and impede the macromolecular chains folding.

\subsubsection{Miscibility in the blends}

Rheology in the melt state.

Figure 3 reports the $\eta^{0}$ data for the five systems as a function of their composition. Even though the choice of the temperature has an incidence on the $\eta^{0}$ values, it does not change the observed evolutions as a function of composition [3]. It is noteworthy that 7030 and 3070 blends roughly obey an additivity mixing rule. This suggests miscibility of the PE and PEcB chains, as often claimed in literature in similar circumstances for various kinds of blends including PE-based polymers [1,3,47-49]. 


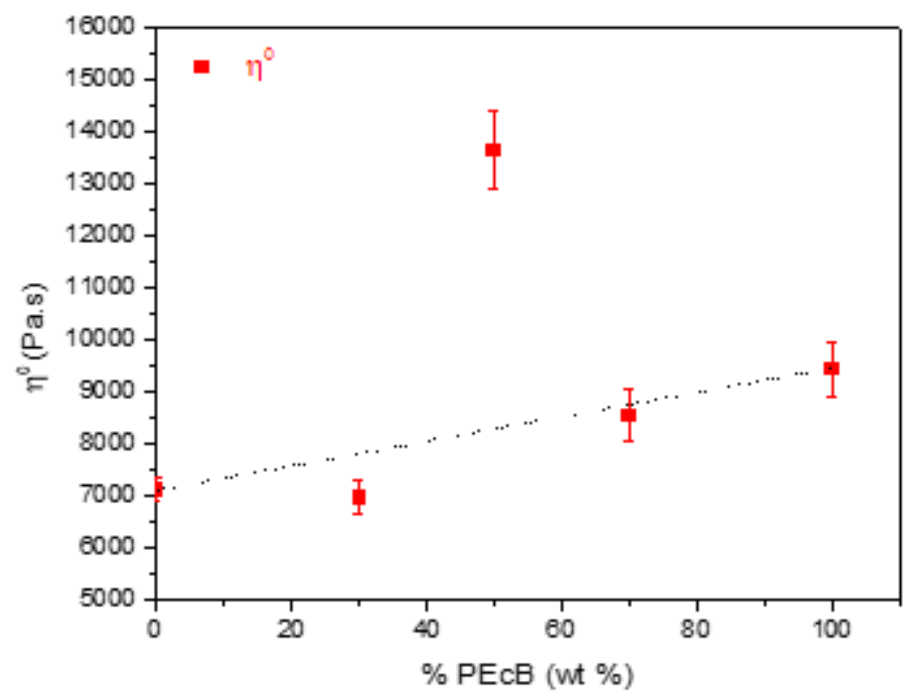

Fig. 3 - Zero-shear viscosity $\eta^{0}$ at $140^{\circ} \mathrm{C}$ for the PE/PEcB blends as a function of composition. Converely, the 5050 system displays a large amplitude of $\eta^{0}$ value which does not follow the mixing law. This can be ascribed to an emulsion-like behavior, otherwise immiscibility. Besides, the positive sign and the high amplitude of this deviation are indicative of strongly favorable interactions at the interfaces of the segregated phases as reported in a previous study [3].

3.2. Part 2: thermo-oxidation of the polymers and blends: impact of the physical state on their degradation behavior

\subsubsection{Spectroscopy analysis before ageing}

\subsection{1.a Influence of crosslinking}

IR analysis.

The influence of the crosslinking process was investigated by comparing the IR spectra of PE and PEr, as well as those of PEcB and PEcBr (Figure 4).

A slight increase of the absorbance at $1730 \mathrm{~cm}^{-1}$ can be noticed in the IR spectrum of both crosslinked polyethylenes, and suggests that oxidation products could be formed during crosslinking at $180^{\circ} \mathrm{C}$. Otherwise crosslinking leads to non detectable modifications of the other parts of the infrared spectra. 

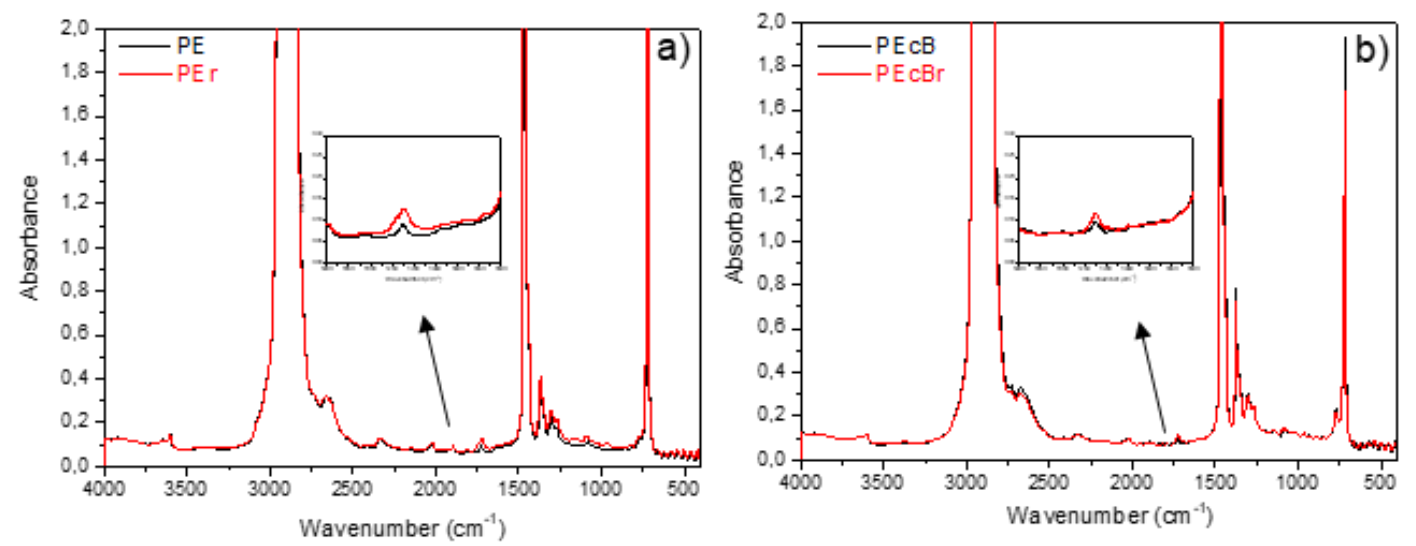

Fig. 4 - IR spectra of a) PE and PEr films b) PEcB and PEcBr films.

\subsection{1.b Influence of blend composition}
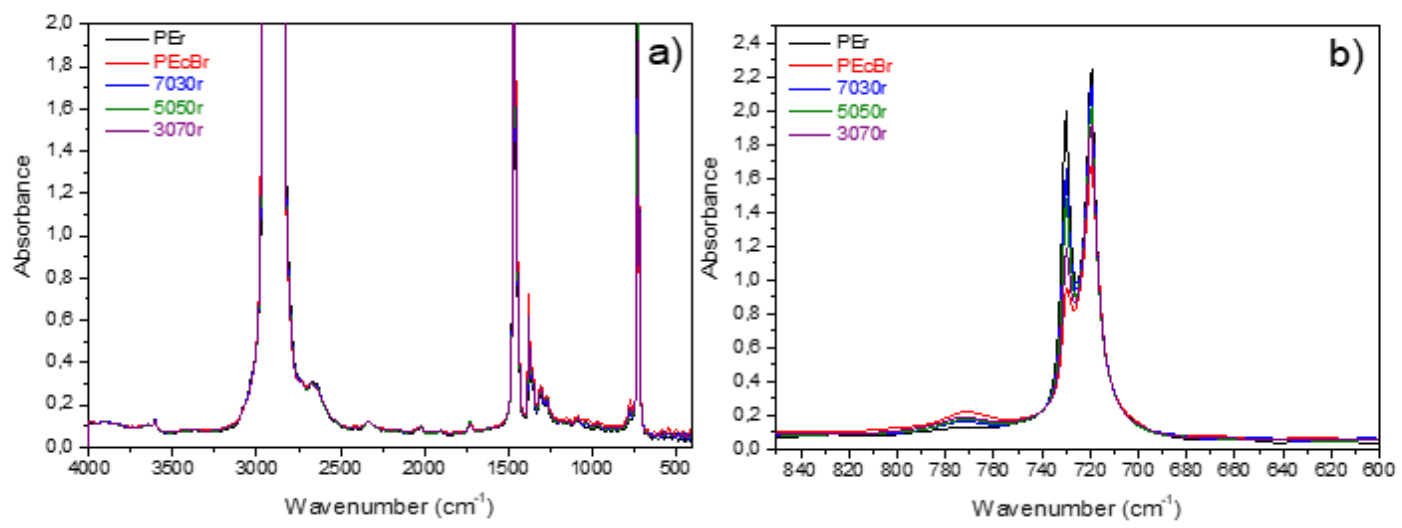

Fig. 5 - a) FTIR spectra of PEr/PEcBr blends; b) in the region between 850 and $600 \mathrm{~cm}^{-1}$.

Figure 5 displays the IR spectra of the $\mathrm{PEr} / \mathrm{PEcBr}$ crosslinked blends. It shows the characteristic IR absorption bands of polyethylene. Only different intensities of the bands at $730 \mathrm{~cm}^{-1}$ and $720 \mathrm{~cm}^{-1}$ are observed, depending on the blends. These bands are ascribed to methylene rocking mode bands [44]. A broad band at $723 \mathrm{~cm}^{-1}$ associated to the amorphous fraction significantly overlaps the two narrow bands of the crystalline fraction. 


\subsubsection{Spectroscopy analysis after ageing}

IR analysis.
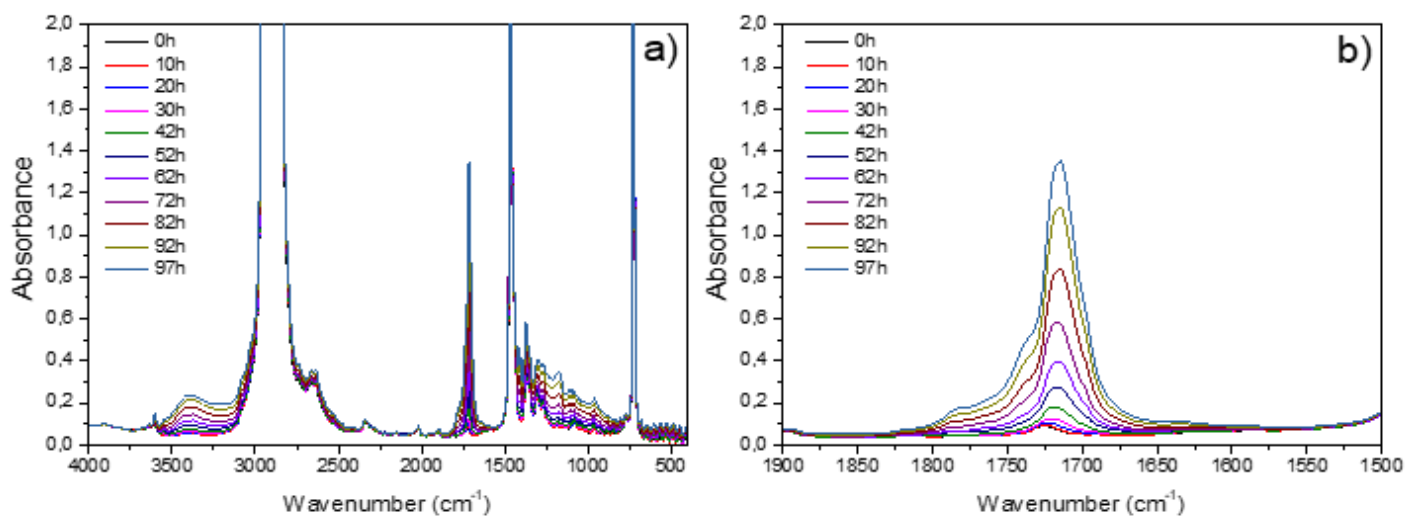

Fig. 6 - a) Infrared spectra of a $80 \mu$ m-thick PEr film during thermal oxidation at $110^{\circ} \mathrm{C}$; b) in the region between 1900 and $1500 \mathrm{~cm}^{-1}$.

Figure 6 shows the infrared spectra of a $80 \mu \mathrm{m}$ thick PEr film during thermal oxidation at $110^{\circ} \mathrm{C}$. Note that the question of having diffusion-limited oxidation effects in the films has been raised during the experiments. No marked oxidation profile on highly thermo-oxidized thick samples $(400-500 \mu \mathrm{m})$ at $110^{\circ} \mathrm{C}$ could be observed on pure polyethylenes.

The formation of the same new absorption bands in the infrared spectra were observed for all the ageing temperatures and all the samples, thus for sake of clarity only thermo-oxidized PEr at $110^{\circ} \mathrm{C}$ is presented.

The main modifications of the chemical structure revealed by IR analysis occured in three domains: hydroxyl (3500-3000 $\left.\mathrm{cm}^{-1}\right)$, carbonyl (1900-1500 $\left.\mathrm{cm}^{-1}\right)$ and fingerprint regions $\left(1500-600 \mathrm{~cm}^{-1}\right)$. The formation of a broad band between 3500 and $3000 \mathrm{~cm}^{-1}$ was observed, with two absorption maxima at $3420 \mathrm{~cm}^{-1}$ and $3550 \mathrm{~cm}^{-1}$ that can be observed after subtraction of the spectrum recorded before ageing. These bands are known to come from the formation of monomeric hydroperoxides $\left(3550 \mathrm{~cm}^{-1}\right)$ and hydrogen-bonded alcohols and hydroperoxides $\left(3420 \mathrm{~cm}^{-1}\right)[4,9,52,53]$.

As frequently reported in the literature $[4,19,54]$, the modification of the spectrum in the carbonyl domain (1900-1500 $\left.\mathrm{cm}^{-1}\right)$ indicates that ketones $\left(1720 \mathrm{~cm}^{-1}\right)$ are formed in the initial steps, and carboxylic acids $\left(1714 \mathrm{~cm}^{-1}\right)$, esters $\left(1735 \mathrm{~cm}^{-1}\right)$ and lactones $\left(1780 \mathrm{~cm}^{-1}\right)$ form in secondary processes. 
In the region between 1500 and $600 \mathrm{~cm}^{-1}$, several modifications were noticed. The main feature was the increase of absorbance of a broad band with a maximum at $1170 \mathrm{~cm}^{-1}$, corresponding to $\mathrm{C}-\mathrm{O}$ bonds of the carbonyl products.

\section{Chemical treatments.}

$\mathrm{NH}_{3}$ treatments were carried out on thermo-oxidized $\mathrm{PEr}$ and $\mathrm{PEcBr}$ films $(80 \mu \mathrm{m}) . \mathrm{NH}_{3}$ reactions led to a decrease of the intensity of the carbonyl band around $1714 \mathrm{~cm}^{-1}$ and 1740 $\mathrm{cm}^{-1}$ and to the formation of an absorption band at $1550 \mathrm{~cm}^{-1}$ (Figure 7) for both polyethylenes. This last absorption band reveals the formation of carboxylate ions obtained by neutralisation of carboxylic acids $\left(1714 \mathrm{~cm}^{-1}\right)$. No absorption band around $1670 \mathrm{~cm}^{-1}$ was observed, that would have been attributed to amide resulting from the reaction of $\mathrm{NH}_{3}$ with esters, even if a decrease of the esters absorption band at $1740 \mathrm{~cm}^{-1}$ was noticed. It can be concluded that the esters concentration in thermo-oxidized $\mathrm{PEr}$ and $\mathrm{PEcBr}$ films remains fairly low all over the ageing process. It also appears that the band around $1780 \mathrm{~cm}^{-1}$ did not decrease after $\mathrm{NH}_{3}$ treatment. Such a non reactivity suggests that the absorption band observed at $1780 \mathrm{~cm}^{-1}$ rather reflects the presence of lactones than anhydrides.
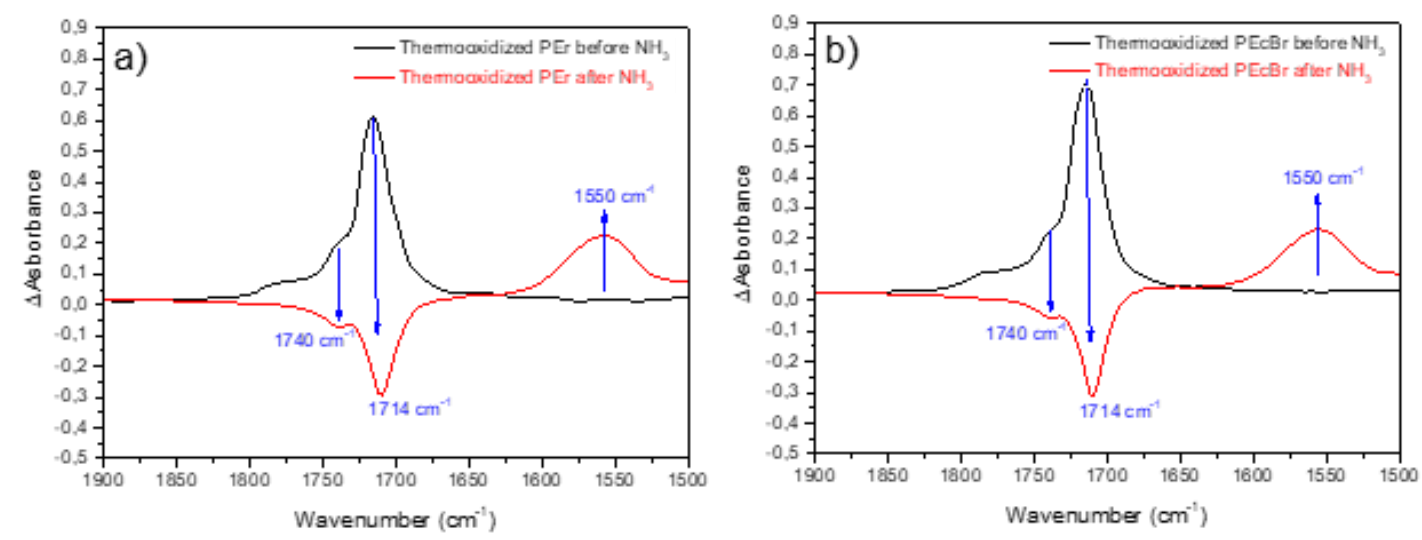

Fig. 7 - Subtracted FTIR spectra $\left(\mathrm{A}_{\mathrm{t}}-\mathrm{A}_{0}\right)$ of thermo-oxidized $\mathrm{PEr}(\mathrm{a})$ and $\mathrm{PEcBr}(\mathrm{b})$ films before and after treatment with $\mathrm{NH}_{3}$.

Treatment with sulfur tetrafluoride $\left(\mathrm{SF}_{4}\right)$ was performed to identify carboxylic acids (Figure 8). Thermo-oxidized PEr and PEcBr films were exposed to $\mathrm{SF}_{4}$ during 15 minutes. Both $\mathrm{PEr}$ and $\mathrm{PEcBr}$ present the same behaviour: the loss of the acid absorption band at $1714 \mathrm{~cm}^{-1}$ and the formation of a new absorption band at $1845 \mathrm{~cm}^{-1}$, attributed to the $\mathrm{C}=\mathrm{O}$ absorption band of aliphatic acid fluorides. This confirms that carboxylic acids are formed during thermal oxidation of both polyethylenes. 

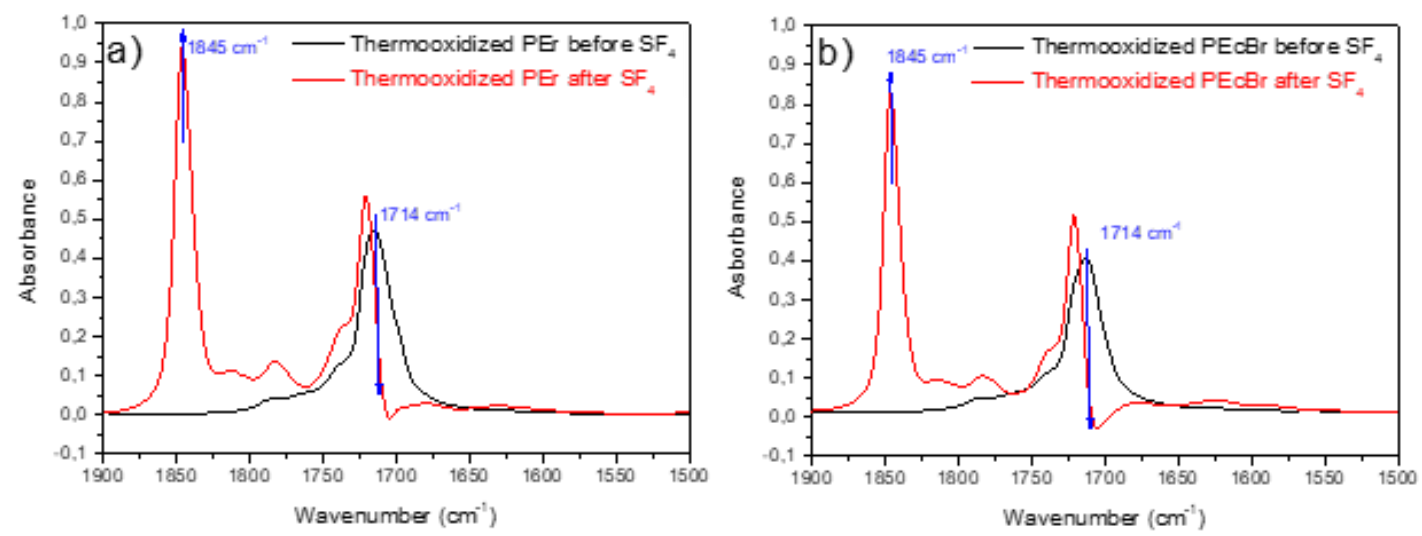

Fig. 8 - Subtracted FTIR spectra $\left(\mathrm{A}_{\mathrm{t}}-\mathrm{A}_{0}\right)$ of thermo-oxidized PEr (a) and PEcBr (b) films before and after treatment with $\mathrm{SF}_{4}$.

Treatment with 2,4-dinitrophenylhydrazine (2,4-DNPH) was used to identify ketones and/or aldehydes in thermo-oxidized $\mathrm{PEr}$ and $\mathrm{PEcBr}$ samples. Infrared spectra after 2,4-DNPH treatment show that the absorption band around $1720 \mathrm{~cm}^{-1}$, which was ascribed to ketones and/or aldehydes $\mathrm{C}=\mathrm{O}$ absorption, decreased while two new absorption bands at $1618 \mathrm{~cm}^{-1}$ and $1594 \mathrm{~cm}^{-1}$ were formed (Figure 9). These two absorption bands are characteristic of 2,4dinitrophenylhydrazone absorption. Moreover, UV-visible analysis of treated $\mathrm{PEr}$ and $\mathrm{PEcBr}$ films showed a strong absorption band around $360 \mathrm{~nm}$, attributed to 2,4dinitrophenyhydrazone absorption (Figure 10). This confirms the same behaviour of both polyethylenes ( $\mathrm{PEr}$ and $\mathrm{PEcBr}$ ), as ketones and/or aldehydes are formed during thermal oxidation.
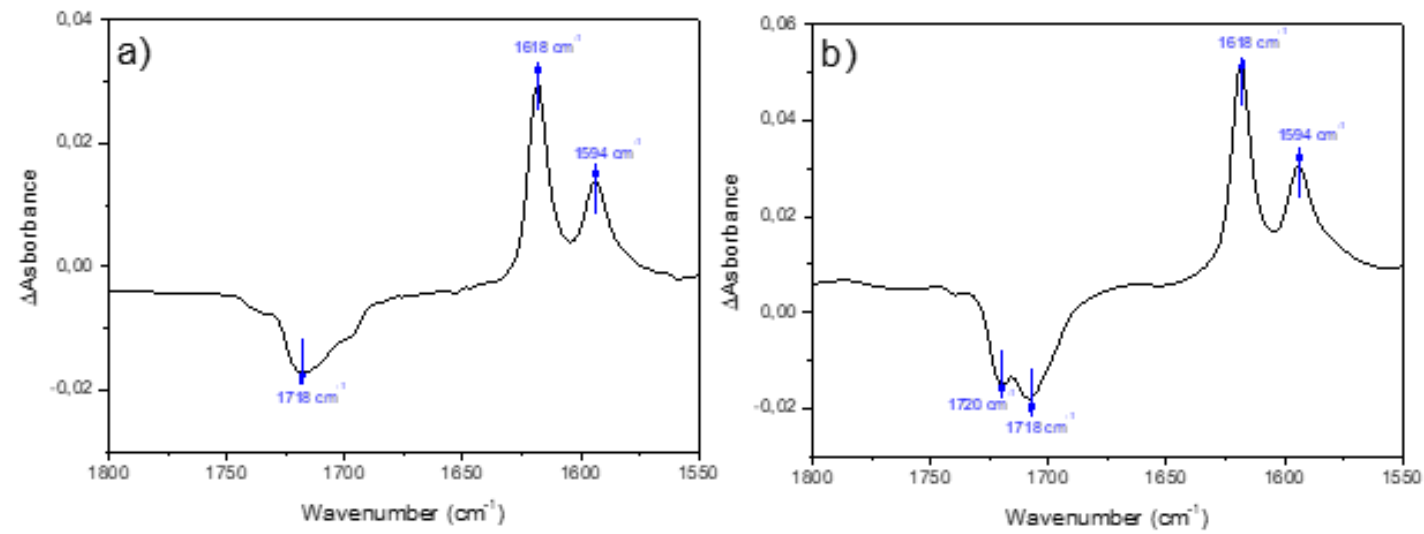

Fig. 9 - Subtracted FTIR spectra $\left(\mathrm{A}_{\mathrm{t}}-\mathrm{A}_{0}\right)$ of thermo-oxidized $\mathrm{PEr}(\mathrm{a})$ and $\mathrm{PEcBr}(\mathrm{b})$ films after treatment with 2,4-DNPH. 

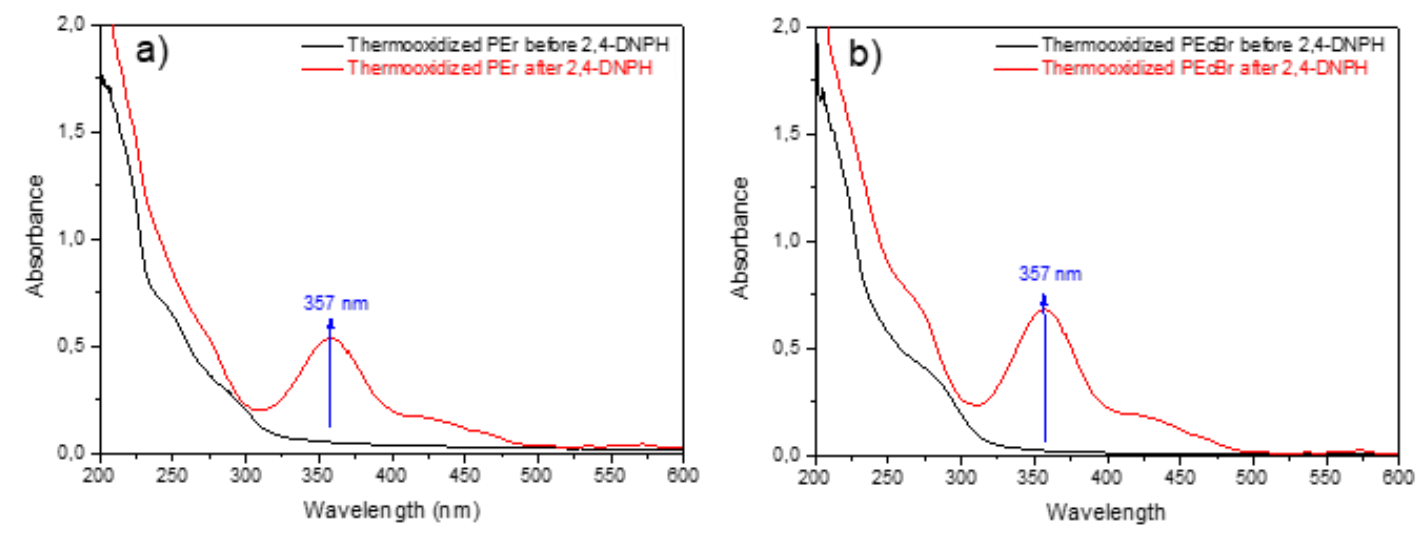

Fig. 10 - UV-visible spectra of thermo-oxidized $\mathrm{PEr}$ (a) and $\mathrm{PEcBr}$ (b) films before and after treatment with 2,4-DNPH.

These chemical derivatization treatments allowed confirming the presence of aliphatic carboxylic acids, lactones, ketones and/or aldehydes as products of the thermal oxidation of $\mathrm{PEr}$ and PEcBr. The thermo-oxidation mechanism of polyethylene already proposed by Gardette et al.[4] could be then confirmed and completed. An important result of this study was that no difference were observed between $\mathrm{PEr}$ and $\mathrm{PEcBr}$ concerning the chemical functions. Thus, this indicates that, in our case, butene content (respectively $3.4 \%$ for PE and $9.4 \%$ for $\mathrm{PEcB}$ ) does not show any influence on the functions of the oxidation products that were detected.

\section{Thermo-oxidation mechanism.}

A comprehensive mechanism of polyethylene thermo-oxidation can be proposed on the basis of the previously identified low molecular weight oxidation products that were formed (Scheme 1), and as already reported in the literature [4]. Thermal oxidation is induced by thermally unstable structures, generaly formed during synthesis and polymer processing. After hydrogen abstraction, the formed radicals react rapidly in the presence of oxygen to form hydroperoxides. Their thermal decomposition leads to the formation of carboxylic acids, alcohols, ketones and esters. These degradation products could be identified through the chemical derivatization treatments shown above, and confirm this mechanism. 


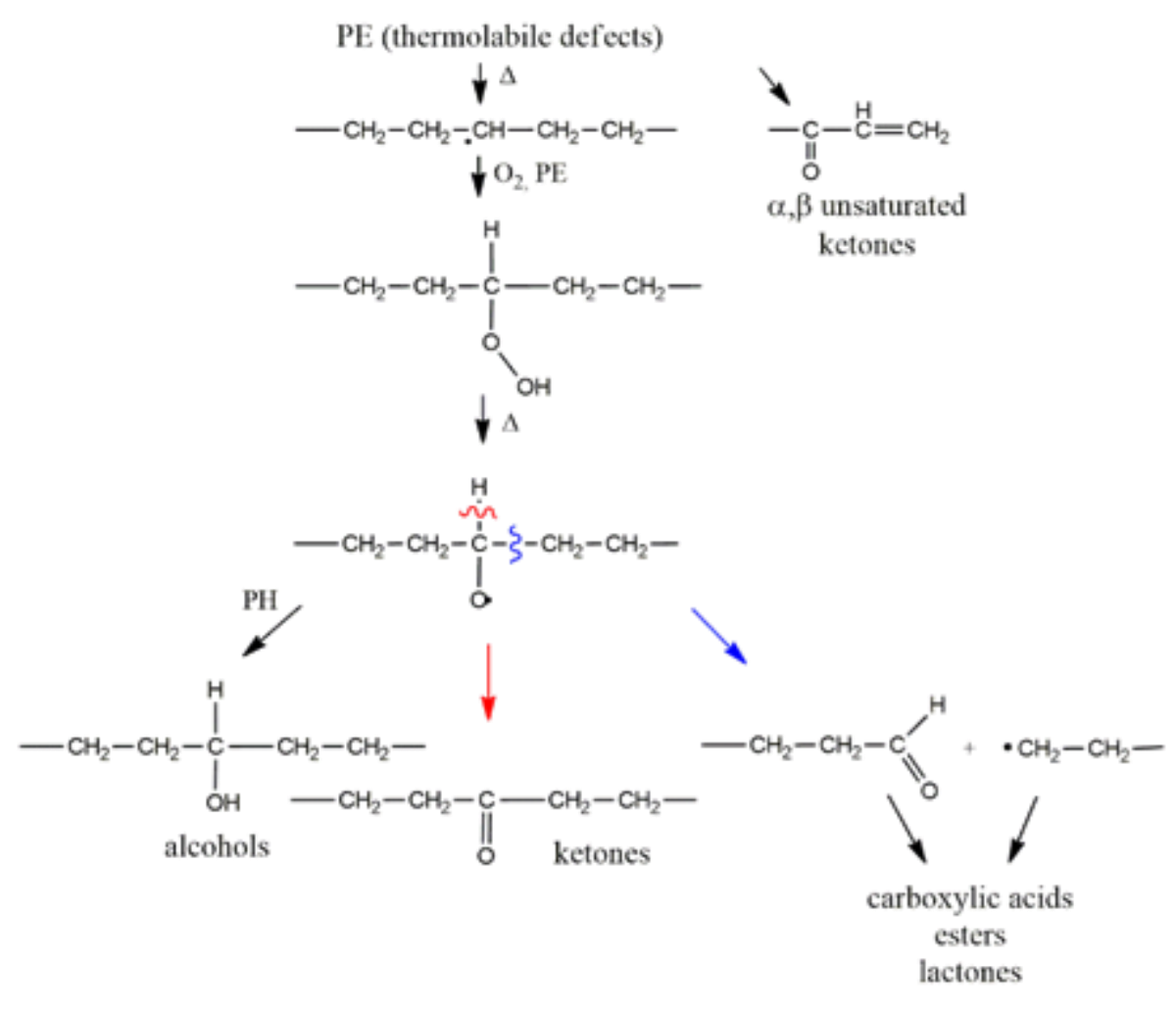

Scheme 1 - Degradation products of polyethylene from the comprehensive thermo-oxidation mechanism of PE [4].

\subsubsection{Kinetics of oxidation}

The rates of thermo-oxidation of the two polyethylenes and the three blends can be compared by measuring the increase of absorbance at $1714 \mathrm{~cm}^{-1}$ corresponding to the accumulation of oxidation products (mainly carboxylic acids) in the polymer matrix with the exposure time at the five ageing temperatures: $60^{\circ} \mathrm{C}, 80^{\circ} \mathrm{C}, 100^{\circ} \mathrm{C}, 90^{\circ} \mathrm{C}, 110^{\circ} \mathrm{C}$ (Figure 11).

The five graphs in Figure 11 show that the absorbance at $1714 \mathrm{~cm}^{-1}$ increases with an exponential curvature. Comparing the curves of Figure 14 suggests several comments. The 5050r blend oxidizes much faster than the other blends. However, as the kinetic curves of PEr and $\mathrm{PEcBr}$ are similar, one cannot ascribe this to the amount of butene as it does not seem to affect the rate of formation of the oxidation products. Another important result that can be deduced is that the physical state of the polymers has no influence on the kinetics of thermooxidation. PEr, PEcBr, 7030r and 3070r have indeed the same rate of oxidation for a given temperature, even though it was previously shown that their crystallinity is different. This is true for all the investigated temperatures. Only the 5050r blend has a peculiar behavior at all 
ageing temperatures, with an oxidation rate which is always higher than that of the other samples. This could be related to the results of rheology in the melt state reported above, which indicated that the 5050 blend was not obeying the additivity mixing rule, reflecting a partial immiscibility of both $\mathrm{PE}$ and $\mathrm{PEcB}$ in this blend. This would suggest that immiscibility of these two polymers in a blend leads to a higher degradation. Note that Singh et al.[56] have indeed reported a higher degradation in LLDPE/PLLA blends under thermo-oxidative conditions compared to pure polymers, ascribed to the bad miscibility between LLDPE and PLLA in the blends.
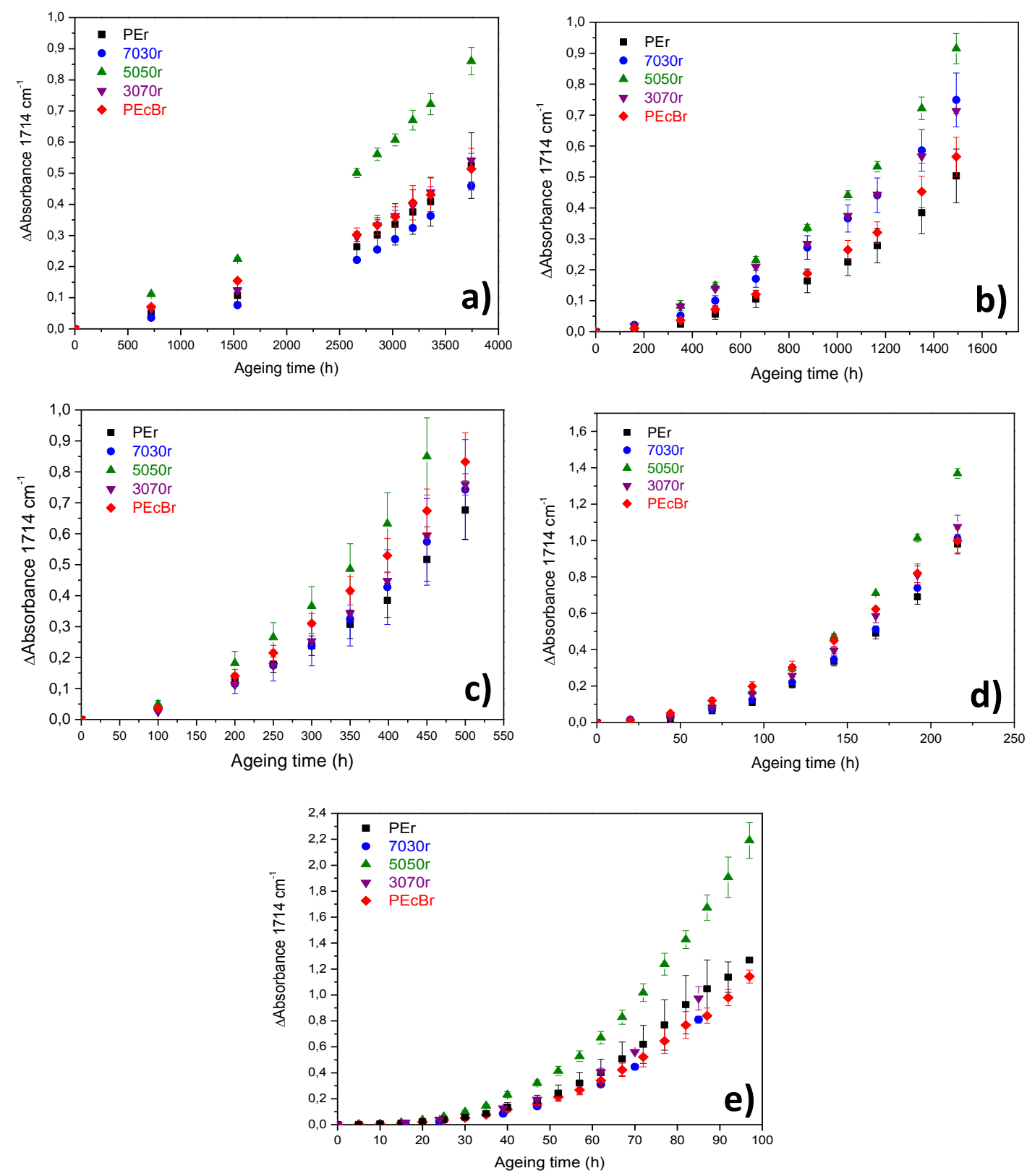

Fig. 11. Kinetic curves for $\mathrm{PEr}$ and $\mathrm{PEcBr}$ and the three blends during thermo-oxidation at a) $\left.\left.60^{\circ} \mathrm{C} \mathrm{b)} 80^{\circ} \mathrm{C} \mathrm{c}\right) 90^{\circ} \mathrm{C} \mathrm{d}\right) 100^{\circ} \mathrm{C}$ e) $110^{\circ} \mathrm{C}$. 


\subsubsection{Reliability of extrapolation from Arrhenius' law for lifetime prediction}

An Arrhenius approach has been applied to study the representativeness of accelerated ageing (at $\mathrm{T}>80^{\circ} \mathrm{C}$ ) with respect to ageing in use conditions $\left(\mathrm{T}=60^{\circ} \mathrm{C}\right)$. This approach assumes that a chemical degradation process is controlled by a reaction rate $k$ proportional to $\exp \left(-\mathrm{E}_{\mathrm{a}} / \mathrm{RT}\right)$, where $E_{a}$ is the activation energy, $R$ the gas constant, $T$ the absolute temperature $(K)$ and $A$ the pre-exponential factor (equation 4).

$$
k=A \cdot \exp \left(-\frac{E_{a}}{R T}\right)
$$

The data obtained at different ageing temperatures are analyzed in order to obtain an estimation of $E_{a}$ value, assuming that $E_{a}$ is constant whatever the ageing temperature. This could then allow us to make the lifetime prediction at lower temperatures possible by extrapolation of the data obtained at higher temperatures. It must be noted that this approach is only allowed when the data points of the $\ln (k)=f(1 / T)$ curve, where $k$ is the degradation parameter, produces straight lines, whose slope is $-E_{a} / R$.

A classical approach has been used to measure the activation energy: the ageing time $t$ corresponding to a $\Delta$ Absorbance value equal to 0.5 has been measured on the kinetic curves for each sample at each ageing temperature. The obtained values are listed in Table 4. Then, the values of $\ln (t)$ at the different temperatures investigated have been plotted against 1/T for each sample (black squares) (Figure 12).

Table 4 - Ageing time $t(\mathrm{~h})$ corresponding to $\Delta$ Absorbance $=0.5$, estimated on the kinetic curves (Figure 14).

\begin{tabular}{|c|c|c|c|c|c|}
\hline Agample & $\mathbf{6 0}^{\circ} \mathbf{C}$ & $\mathbf{8 0}^{\circ} \mathbf{C}$ & $\mathbf{9 0}^{\circ} \mathbf{C}$ & $\mathbf{1 0 0}{ }^{\circ} \mathbf{C}$ & $\mathbf{1 1 0}^{\circ} \mathbf{C}$ \\
\hline $\mathbf{P E r}$ & 3750 & 1500 & 450 & 167 & 67 \\
\hline $\mathbf{7 0 3 0 r}$ & 4000 & 1250 & 425 & 167 & 72 \\
\hline $\mathbf{5 0 5 0 r}$ & 2670 & 1100 & 350 & 142 & 56 \\
\hline $\mathbf{3 0 7 0 r}$ & 3640 & 1250 & 425 & 156 & 67 \\
\hline $\mathbf{P E c B r}$ & 3750 & 1400 & 390 & 150 & 72 \\
\hline
\end{tabular}


It is important to note that other characteristics, graphically determined from the kinetic curves at $1714 \mathrm{~cm}^{-1}$, have been investigated in order to use the complete data set of the oxidation curves. The Arrhenius approach has been applied on six characteristics: time $t_{0.2}, t_{0.5}$ and $t_{0.8}$ corresponding to $\Delta \mathrm{Abs}=0.2, \Delta \mathrm{Abs}=0.5, \Delta \mathrm{Abs}=0.8$, the induction time $\mathrm{t}_{\mathrm{i}}$ (which is considered as the weakest increase of absorbance that can be detected - this is rather subjective and the precision is very low), the maximum oxidation rate $\mathrm{r}_{\mathrm{s}}$ (given by the slope of the tangent of the kinetic curve in the steady state), and the time corresponding to the point of intersection $\theta_{\mathrm{i}}$ between the tangent and the abscissa axis. However, the results showed no decent superposition. 

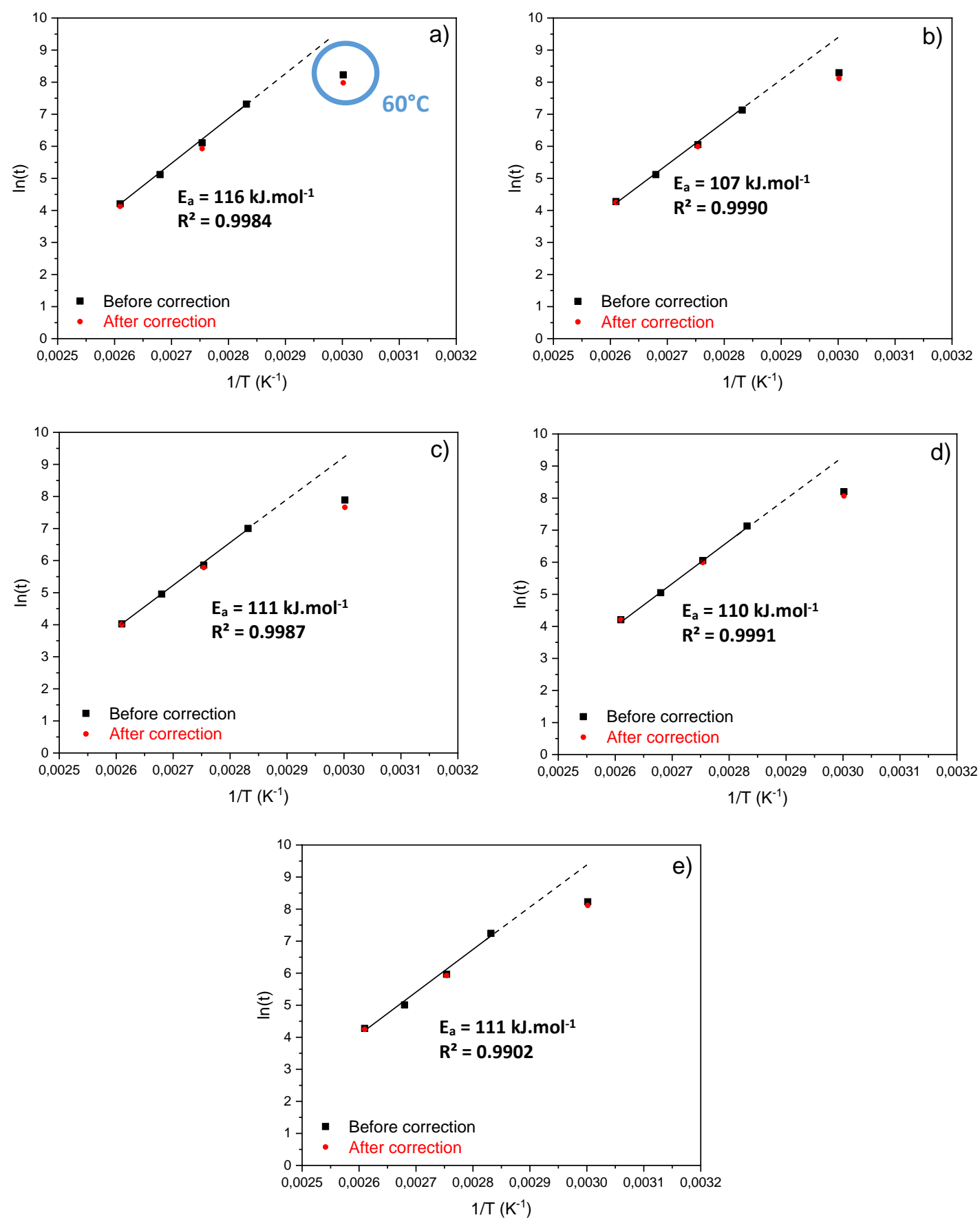

Fig. 12. Arrhenius plot of the ageing time $t$ corresponding to $\Delta$ Absorbance $=0.5$ (before and after correction by the amorphous phase fraction) for a) PEr b) 7030r c) 5050r d) 3070r e) $\mathrm{PEcBr}$.

One can observe that the data points related to thermal ageing between $80^{\circ} \mathrm{C}$ and $110^{\circ} \mathrm{C}$ can be fitted a by straight line. The slopes are similar for the various temperatures, which gives an

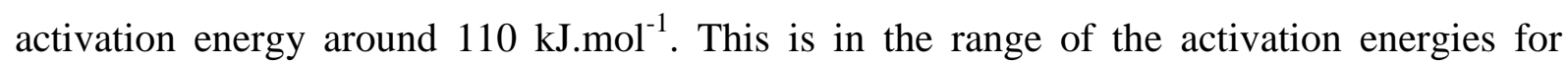
thermal oxidation of many polymers reported in the literature $[24,25,30]$. In contrast, the data 
point corresponding to thermal ageing at $60^{\circ} \mathrm{C}$ is systematically out of this straight line. This indicates that the oxidation kinetics, and more specifically the ageing time necessary to reach a $\Delta$ Asborbance value equal to 0.5 , obey then the Arrhenius' law only in the temperature range $80-110^{\circ} \mathrm{C}$. At the opposite, below $80^{\circ} \mathrm{C}$, the activation energy may be different. As a direct consequence, for all the samples, no extrapolation of the data obtained at temperatures above $80^{\circ} \mathrm{C}$ to lower temperatures should be performed without making critical errors, especially since ageing at $60^{\circ} \mathrm{C}$ is actually more severe than the prediction of the extrapolation.

Note that a break of the Arrhenius plot has already been reported by Langlois et al.[57] in the case of electron beam crosslinked polyethylene thermo-oxidized between 110 and $180^{\circ} \mathrm{C}$. The Arrhenius law was applied to several criteria (phenol and carbonyl depletion, density, weight loss, elongation at break), and all the curves displayed a discontinuity at $120-130^{\circ} \mathrm{C}$. The authors ascribed this observation to the melting transition of the crosslinked polyethylene at this temperature.

\section{Influence of the physical state?}

In order to verify this hypothesis, a correction factor was applied to the oxidation kinetics, for the purpose of comparing them without the influence of crystallinity. The kinetic curves ( $\triangle$ Absorbance at $1714 \mathrm{~cm}^{-1}$ as a function of ageing time) were corrected by dividing each $\Delta$ Absorbance value by the fraction of amorphous phase in the polymer during thermal ageing, estimated from the DSC curves of the samples, at each ageing time. The data were corrected at three ageing temperatures : $60^{\circ} \mathrm{C}, 90^{\circ} \mathrm{C}$ and $110^{\circ} \mathrm{C}$. For sake of clarity, the oxidation kinetics at $1714 \mathrm{~cm}^{-1}$ corrected by the amount of amorphous phase are presented in Annex B (Figure B.1.). The same Arrhenius approach (Figure 12) was then applied to the corrected data: the ageing time $t$ corresponding to a $\Delta$ Absorbance value equal to 0.5 has been read on the kinetic curves for each sample at each ageing temperature. The new data points obtained (red circles) quasi-superpose to the previous ones (see Figure 12 above), indicating that the amorphous correction has no significant influence on the previous conclusion. Thus, the difference in the crystalline microstructure of the materials at the different ageing temperature cannot be at the origin of the disagreement between the experimental data and their Arrhenius extrapolation at $60^{\circ} \mathrm{C}$. Khelidj et al.[58] also observed a discontinuity of the Arrhenius graph around $80^{\circ} \mathrm{C}$ in the case of linear PE, but they rather suspected a change of the oxidation mechanism, which is in agreement with the theory of Celina et al.[30]. 


\section{Conclusion}

The study of the thermooxidative degradation of a crosslinked linear polyethylene/branched polyethylene blend has shown three main results. First, the thermo-oxidation mechanism of both polyethylenes was confirmed thanks to chemical derivatization treatments. Then, the 5050r blend contains more carbonylated oxidation products than the other samples for a given ageing time and ageing temperature. The hypothesis of a partial immiscibility of both PE and $\mathrm{PEcB}$ in this blend, as shown by rheology in the melt state experiments, could explain its higher degradation. Finally, the non-Arrhenius behavior of the thermal degradation of these material in the $60^{\circ} \mathrm{C}-110^{\circ} \mathrm{C}$ temperature domain was evidenced. The impact of the ageing temperature on the physical state of the polymers cannot be an explanation to this as there is no significant influence of the amorphous phase content on the experimental oxidation kinetics (characterised here by the IR absorbance variation at $1714 \mathrm{~cm}^{-1}$ ). Thus, our study evidences that, in the case of crosslinked $\mathrm{PE} / \mathrm{PEcB}$ blends, accelerated ageing tests keep their predictive value in a quite limited temperature range $\left(80^{\circ} \mathrm{C} \leq \mathrm{T} \leq 110^{\circ} \mathrm{C}\right)$, but are not representative of thermal degradation at temperature in use conditions (typically in a domain where $50^{\circ} \mathrm{C} \leq \mathrm{T} \leq 70^{\circ} \mathrm{C}$ ).

\section{Acknowledgments}

The authors wish to thank the Materials Ageing Institute (MAI-SN) for the financial support, Guillaume Gallot and Jean-François Larché (Nexans Research Center) for sample preparation, and Olivier Boyron (C2P2 Lyon) for SEC measurements. 


\section{References}

[1] J. Xu, X. Xu, L. Chen, L. Feng, W. Chen, Effect of composition distribution on miscibility and co-crystallization phenomena in the blends of low density polyethylene with conventional and metallocene-based ethylene \pm butene copolymers, Polymer. 42 (2001) 3867-3874.

[2] C. Liu, J. Wang, J. He, Rheological and thermal properties of m-LLDPE blends with mHDPE and LDPE, Polymer. 43 (2002) 3811-3818.

[3] C. Frederix, J.M. Lefebvre, C. Rochas, R. Séguéla, G. Stoclet, Binary blends of linear ethylene copolymers over a wide crystallinity range: Rheology, crystallization, melting and structure properties, Polymer. 51 (2010) 2903-2917.

[4] M. Gardette, A. Perthue, J.-L. Gardette, T. Janecska, E. Földes, B. Pukánszky, S. Therias, Photo- and thermal-oxidation of polyethylene: Comparison of mechanisms and influence of unsaturation content, Polym. Degrad. Stabil. 98 (2013) 2383-2390.

[5] L.E. Pimentel Real, M.B. Correia, A comparative study on the thermo-oxidative stability of polyethylene, Polym. Test. 31 (2012) 963-969.

[6] J. Lacoste, D.J. Carlsson, Gamma-, Photo-, and Thermally-Initiated Oxidation of linear low Density Polyethylene: A Quantitative Comparison of Oxidation Products, J. Polym. Sci., Part A: Polym. Chem. 30 (1992) 493-500.

[7] H. Vogt, H. Enderle, U. Schulte, J. Hessel, Thermal ageing of PE 100 pipes for accelerated lifetime prediction under service conditions, Plastics Pipes XIV Budapest, Hungary. (2008).

[8] E.M. Hoàng, N.S. Allen, C.M. Liauw, E. Fontán, P. Lafuente, The thermo-oxidative degradation of metallocene polyethylenes. Part 1: Long-term thermal oxidation in the solid state, Polym. Degrad. Stabil. 91 (2006) 1356-1362.

[9] F. Khabbaz, A.C. Albertsson, S. Karlsson, Chemical and morphological changes of environmentally degradable polyethylene films exposed to thermo-oxidation, Polym. Degrad. Stabil. 63 (1999) 127-138.

[10] A.F. Reano, A. Guinault, E. Richaud, B. Fayolle, Polyethylene loss of ductility during oxidation: Effect of initial molar mass distribution, Polym. Degrad. Stabil. 149 (2018) 78-84.

[11] J.-I. Weon, Effects of thermal ageing on mechanical and thermal behaviors of linear low density polyethylene pipe, Polym. Degrad. Stabil. 95 (2010) 14-20. 
[12] Maryudi, Anwaruddin Hisyam, Rosli Mohd Yunus, Mohammad Dalour Hossen Bag, Thermo-oxidative Degradation of High Density Polyethylene Containing Manganese Laurate, Int. J. Eng. Res. Appl. 3 (2013) 1156-1165.

[13] S.F. Chabira, M. Sebaa, C. G'sell, Oxidation and crosslinking processes during thermal aging of low-density polyethylene films, J. Appl. Polym. Sci. (2011) 5200-5208.

[14] B.M. Imane, A. Asma, C.S. Fouad, S. Mohamed, Weathering Effects on the Microstructure Morphology of Low Density Polyethylene, Procedia Soc. Behav. Sci. 195 (2015) 2228-2235.

[15] R. Ferhoum, Analysis of Thermal Ageing Effect (Hold Time - Crystallinity Rate Mechanical Property) on High Density Polyethylene (HDPE), Int. J. Mater. Sci. Appl. 2 (2013) 109.

[16] B. Fayolle, X. Colin, L. Audouin, J. Verdu, Mechanism of degradation induced embrittlement in polyethylene, Polym. Degrad. Stabil. 92 (2007) 231-238.

[17] M. Celina, G.A. George, Characterisation and degradation studies of peroxide and silane crosslinked polyethylene, Polym. Degrad. Stabil. 48 (1995) 297-312.

[18] K.E. Figueroa, Thermoanalytical study of an aged XLPE-pipe, Thermochim. Acta. 114 (1987) 115-124.

[19] A. Perthué, P.-O. Bussière, M. Baba, J.-F. Larche, J.-L. Gardette, S. Therias, Correlation between water uptake and loss of the insulating properties of PE/ATH composites used in cables applications, Polym. Degrad. Stabil. 127 (2016) 79-87.

[20] L. Boukezzi, A. Boubakeur, C. Laurent, M. Lallouani, DSC Study of Artificial Thermal Aging of XLPE Insulation Cables, in: IEEE (2007) 146-149.

[21] L. Boukezzi, M. Nedjar, L. Mokhnache, M. Lallouani, A. Boubakeur, Thermal aging of cross-linked polyethylene, Annales de Chimie Science Des Matériaux. 31 (2006) 561569.

[22] M. Nedjar, Effect of thermal aging on the electrical properties of crosslinked polyethylene, J. Appl. Polym. Sci. 111 (2009) 1985-1990.

[23] C. Kim, Z. Jin, P. Jiang, Z. Zhu, G. Wang, Investigation of dielectric behavior of thermally aged XLPE cable in the high-frequency range, Polym. Test. 25 (2006) 553561.

[24] K.T. Gillen, R. Bernstein, M. Celina, Non-Arrhenius behavior for oxidative degradation of chlorosulfonated polyethylene materials, Polym. Degrad. Stab. 87 (2005) 335-346. 
[25] K.T. Gillen, R. Bernstein, D.K. Derzon, Evidence of non-Arrhenius behavior from laboratory aging and 24-year field aging of polychloroprene rubber materials, Polym. Degrad. Stab. 87 (2005) 57-67.

[26] K.T. Gillen, M. Celina, R.L. Clough, J. Wise, Extrapolation of accelerated aging data Arrhenius or erroneous?, Trends Polym. Sci. 5 (1997) 250-257.

[27] K.T. Gillen, M. Celina, M.R. Keenan, Methods for predicting more confident lifetimes of seals in air environments, Rubber Chem. Technol. 73 (2000) 265-283.

[28] P. Gijsman, J. Hennekens, J. Vincent, The influence of temperature and catalyst residues on the degradation of unstabilized polypropylene, Polym. Degrad. Stab. 39 (1993) 271-277.

[29] F. Gugumus, Effect of temperature on the lifetime of stabilized and unstabilized PP films, Polym. Degrad. Stab. 63 (1999) 41-52.

[30] M. Celina, K.T. Gillen, R.A. Assink, Accelerated aging and lifetime prediction: Review of non-Arrhenius behaviour due to two competing processes, Polym. Degrad. Stab. 90 (2005) 395-404.

[31] E.T. Hsieh, J.C. Randall, Ethylene-1-butene copolymers. 1. Comonomer sequence distribution, Macromolecules. 15 (1982) 353-360.

[32] A. Nuamthanom, Multidimensional NMR Studies of Poly (ethylene-co-1-octene) Copolymers and Poly (ethylene-co-vinyl Acetate-co-carbon Monoxide) Terpolymers, PhD Thesis, University of Akron (2007).

[33] D.J. Carlsson, R. Brousseau, Can Zhang, D.M. Wiles, Identification of Products from Polyolefin Oxidation by Derivatization Reactions, ACS Symp. Ser. 364 (1988) 376389.

[34] C. Wilhelm, J.-L. Gardette, Infrared identification of carboxylic acids formed in polymer photooxidation, J. Appl. Polym. Sci. 51 (1994) 1411-1420.

[35] B. Wunderlich, Thermal Analysis, Academic Press (1990) 417-431.

[36] R. Androsch, Melting and crystallization of poly (ethylene-co-octene) measured by modulated dsc and temperature-resolved X-ray diffraction, Polymer. 40 (1999) 28052812 .

[37] S. Bensason, J. Minick, A. Moet, S. Chum, A. Hiltner, E. Baer, Classification of Homogeneous Ethylene-Octene copolymers based on comonomer contents, J. Polym. Sci., Part B: Polym. Phys. 34 (1996) 1301-1315. 
[38] H. Wen, H. Li, S. Xu, S. Xiao, H. Li, S. Jiang, L. An, Z. Wu, Shear effects on crystallization behavior of poly(ethylene-co-octene) copolymers, J. Polym. Res. 19 (2012).

[39] A.G. Simanke, G.B. Galland, L. Freitas, J. Alziro H. da Jornada, R. Quijada, R.S. Mauler, Influence of the comonomer content on the thermal and dynamic mechanical properties of metallocene ethylene/1-octene copolymers, Polymer. 40 (1999) 54895495.

[40] H.P. Wang, S.P. Chum, A. Hiltner, E. Baer, Comparing elastomeric behavior of block and random ethylene-octene copolymers, J. Appl. Polym. Sci. 113 (2009) 3236-3244.

[41] S.V. Eynde, V.B.F. Mathot, M.H.J. Koch, H. Reynaers, Thermal behaviour and morphology of homogeneous ethylene-1-octene copolymers with high comonomer contents, Polymer. 41 (2000) 4889-4900.

[42] M. Zhang, D.T. Lynch, S.E. Wanke, Effect of molecular structure distribution on melting and crystallization behavior of 1-butene/ethylene copolymers, Polymer. 42 (2001) 3067-3075.

[43] S.V. Eynde, V. Mathot, M.H.J. Koch, H. Reynaers, Thermal behaviour and morphology of homogeneous ethylene-propylene and ethylene-1-butene copolymers with high comonomer contents, Polymer. 41 (2000) 3437-3453.

[44] Y. Badar, Z. Ali, Characterization of gamma irradiated polyethylene films by DSC and X-ray diffraction techniques, Polym. Int. 49 (2000) 1555-1560.

[45] H.A. Khonakdar, J. Morshedian, M. Mehrabzadeh, U. Wagenknecht, S.H. Jafari, Thermal and shrinkage behaviour of stretched peroxide-crosslinked high-density polyethylene, Eur. Polym. J. 39 (2003) 1729-1734.

[46] H. Brody, Intercristalline crosslinking of polyethylene, J. Polym. Sci. 15 (1971) 9871005.

[47] D. Rana, H. Lim Kim, H. Kwag, S. Choe, Hybrid blends of similar ethylene 1-octene copolymers, Polymer. 41 (2000) 7067-7082.

[48] C.A. Fonseca, I.R. Harrison, An investigation of co-crystallization in LDPE/HDPE blends using DSC and TREF, Thermochim. Acta. 313 (1998) 37-41.

[49] R.L. Morgan, M.J. Hill, P.J. Barham, Morphology, melting behaviour and cocrystallization in polyethylene blends: the effect of cooling rate on two homogeneously mixed blends, Polymer. 40 (1999) 337-348.

[50] R. Koplík, Ultraviolet and visible spectrometry, Theoretical overwiew. http://web.vscht.cz/ poustkaj/EN\%20ASFA\%20AU\%20Kop1\%C3\%ADk\%20UV_VIS _spectrometry.pdf. 
[51] H. Hagemann, R.G. Snyder, A.J. Peacock, L. Mandelkern, Quantitative infrared methods for the measurement of crystallinity and its temperature dependence: polyethylene, Macromolecules. 22 (1989) 3600-3606.

[52] J. Petruj, J. Marchal, Mechanism of ketone formation in the thermooxidation and radiolytic oxidation of low density polyethylene, Radiat. Phys. Chem. 16 (1980) 27-36.

[53] J. Lemaire, R. Arnaud, J.-L. Gardette, Low temperature thermo-oxidation of thermoplastics in the solid state, Polym. Degrad. Stabil. 33 (1991) 277-294.

[54] D.J. Carlsson, R. Brousseau, Can Zhang, D.M. Wiles, Identification of Products from Polyolefin Oxidation by Derivatization Reactions, ACS Symp. Ser. 364 (1988) 376389.

[55] B. Suresh, S. Maruthamuthu, A. Khare, N. Palanisamy, V.S. Muralidharan, R. Ragunathan, M. Kannan, K.N. Pandiyaraj, Influence of thermal oxidation on surface and thermo-mechanical properties of polyethylene, J. Polym. Res. 18 (2011) 21752184 .

[56] G. Singh, H. Bhunia, P.K. Bajpai, V. Choudhary, Thermal degradation and physical aging of linear low density polyethylene and poly(L-lactic acid) blends, J. Polym. Eng. 32 (2012) 59-66.

[57] V. Langlois, L. Audouin, J. Verdu, P. Courtois, Thermooxidative aging of crosslinked linear polyethylene: stabilizer consumption and lifetime prediction, Polym. Degrad. Stabil. 40 (1993) 399-409.

[58] N. Khelidj, X. Colin, L. Audouin, J. Verdu, C. Monchy-Leroy, V. Prunier, Oxidation of polyethylene under irradiation at low temperature and low dose rate. Part II. Low temperature thermal oxidation, Polym. Degrad. Stab. 91 (2006) 1598-1605. 


\section{$\underline{\text { Annex A }}$}
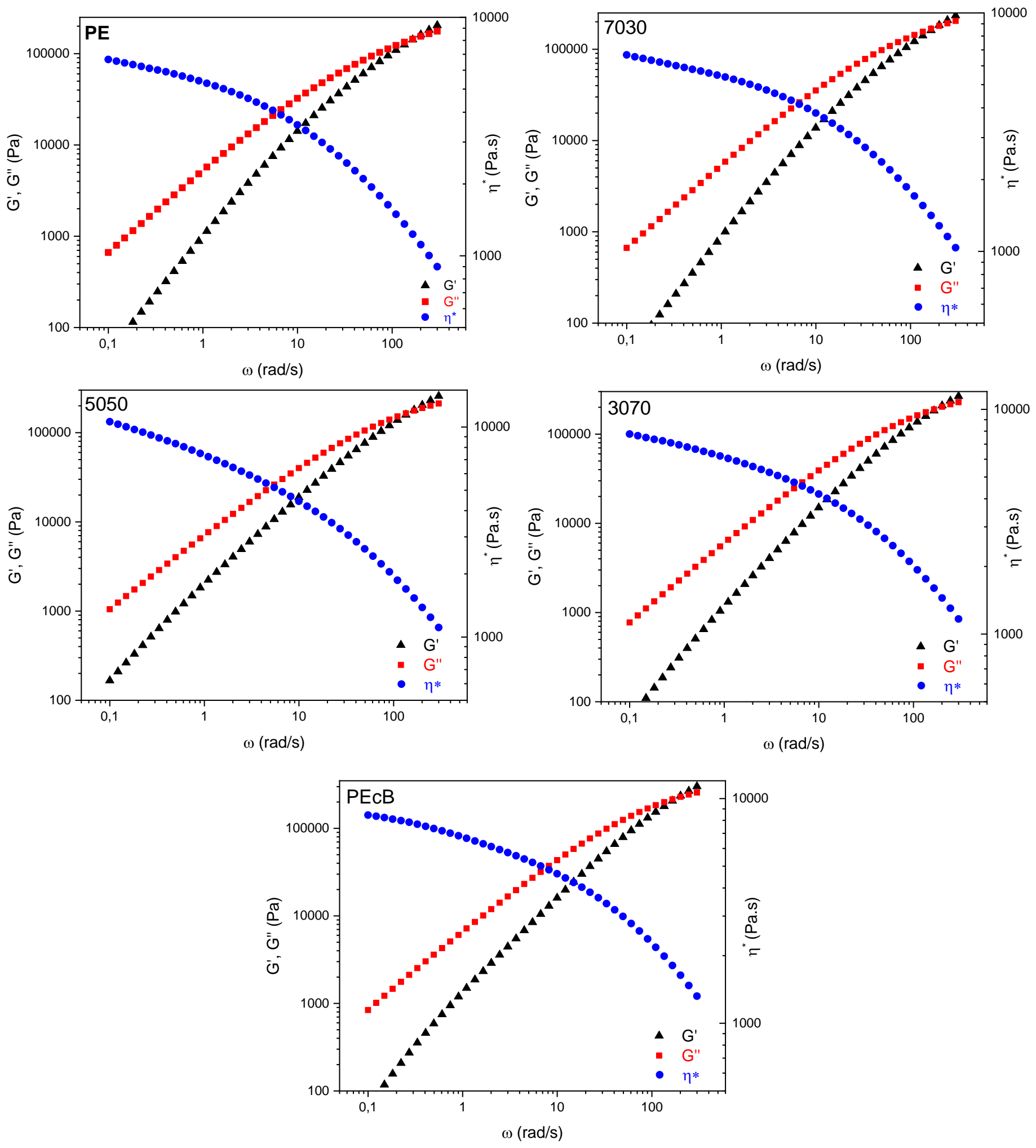

Fig. A.1. Curves obtained from the rheology in the melt state experiments for PE, PEcB and the three blends. 


\section{$\underline{\text { Annex B }}$}
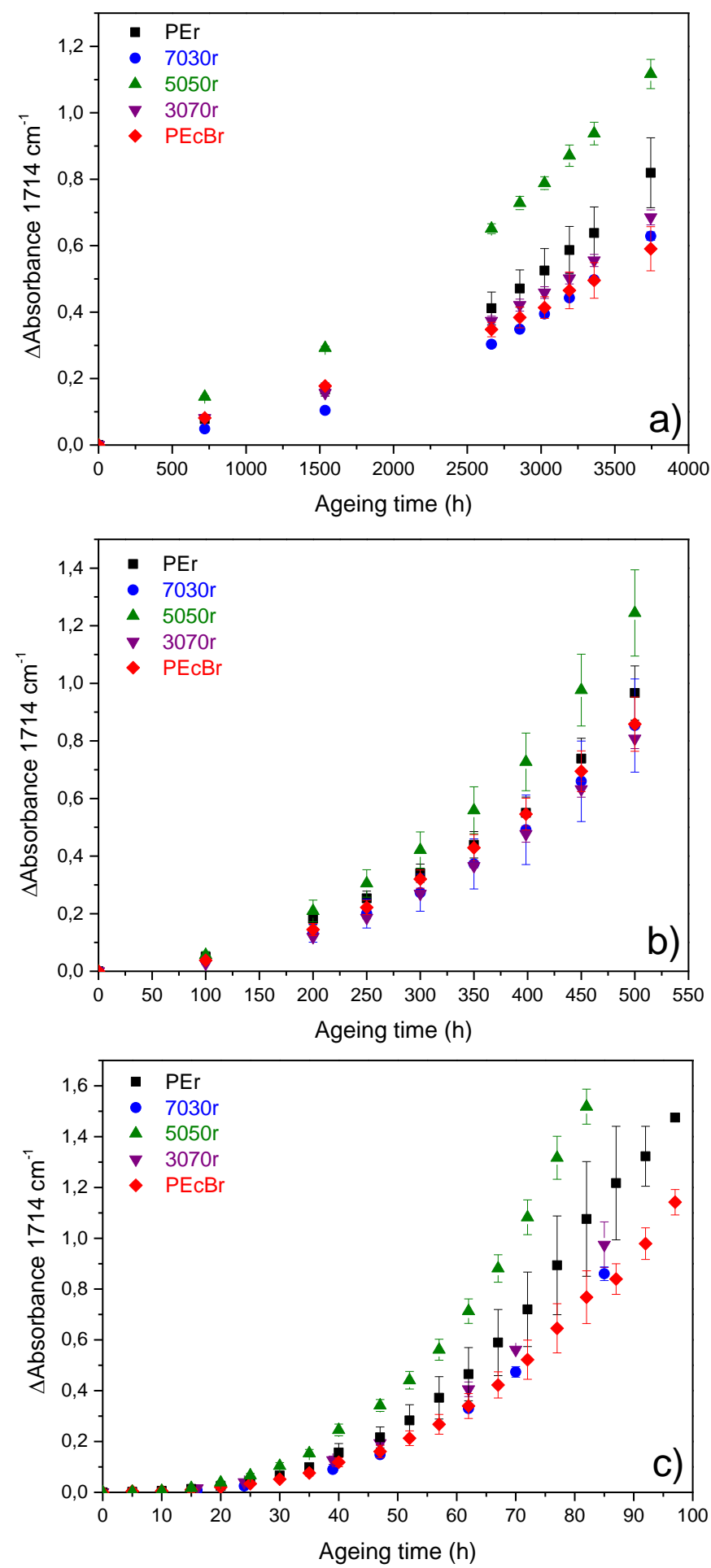

Fig. B.1. Kinetic curves at $1714 \mathrm{~cm}^{-1}$ corrected by the amount of amorphous phase for thermal ageing at a) $\left.60^{\circ} \mathrm{C} \mathrm{b}\right) 90^{\circ} \mathrm{C}$ and c) $110^{\circ} \mathrm{C}$. 


\section{Figure captions}

Fig. 1 - DSC thermograms of the two polymers and the three blends.

Fig. 2 - DSC thermograms of a) PE and crosslinked PEr b) PEcB and crosslinked PEcBr.

Fig. 3 - Zero-shear viscosity $\eta^{0}$ at $140^{\circ} \mathrm{C}$ for the $\mathrm{PE} / \mathrm{PEcB}$ blends as a function of composition.

Fig. 4 - IR spectra of a) PE and PEr films b) PEcB and PEcBr films.

Fig. 5 - a) FTIR spectra of PEr/PEcBr blends; b) in the region between 850 and $600 \mathrm{~cm}^{-1}$.

Fig. 6 - a) Infrared spectra of a $80 \mu$ m-thick PEr film during thermal oxidation at $110^{\circ} \mathrm{C}$; b) in the region between 1900 and $1500 \mathrm{~cm}^{-1}$.

Fig. 7 - Subtracted FTIR spectra $\left(\mathrm{A}_{\mathrm{t}}-\mathrm{A}_{0}\right)$ of thermooxidized PEr (a) and PEcBr (b) films before and after treatment with $\mathrm{NH}_{3}$.

Fig. 8 - Subtracted FTIR spectra $\left(\mathrm{A}_{\mathrm{t}}-\mathrm{A}_{0}\right)$ of thermooxidized PEr (a) and PEcBr (b) films before and after treatment with $\mathrm{SF}_{4}$.

Fig. 9 - Subtracted FTIR spectra $\left(\mathrm{A}_{\mathrm{t}}-\mathrm{A}_{0}\right)$ of thermooxidized $\mathrm{PEr}(\mathrm{a})$ and $\mathrm{PEcBr}(\mathrm{b})$ films after treatment with 2,4-DNPH.

Fig. 10 - UV-visible spectra of thermooxidized $\mathrm{PEr}$ (a) and $\mathrm{PEcBr}$ (b) films before and after treatment with 2,4-DNPH.

Scheme 1 - Degradation products of polyethylene from the comprehensive thermooxidation mechanism of PE [4].

Fig. 11. Kinetic curves for $\mathrm{PEr}$ and $\mathrm{PEcBr}$ and the three blends during thermooxidation at a) $60^{\circ} \mathrm{C}$ b) $\left.\left.80^{\circ} \mathrm{C} \mathrm{c}\right) 90^{\circ} \mathrm{C} \mathrm{d}\right) 100^{\circ} \mathrm{C}$ e) $110^{\circ} \mathrm{C}$.

Fig. 12. Arrhenius plot of the ageing time $t$ corresponding to $\Delta$ Absorbance $=0.5$ (before and after correction by the amorphous phase) for a) PEr b) 7030r c) 5050r d) 3070r e) PEcBr.

Table 1 - Composition of the blends.

Table 2 - Melting temperatures and crystallinity of $500 \mu \mathrm{m}$-thick non-crosslinked polymers and blends.

Table 3 - Melting temperatures and crystallinity of $500 \mu \mathrm{m}$-thick samples before and after crosslinking.

Table 4 - Ageing time $\mathrm{t}(\mathrm{h})$ corresponding to $\Delta$ Absorbance $=0.5$, estimated on the kinetic curves (Figure 14). 